\title{
The Impact of Time Length to Boolean Remission for Tight Disease Activity Control After Acquisition in Rheumatoid Arthritis Patients
}

Ichiro Yoshii ( $\square$ ichiroyo@giga.ocn.ne.jp )

Yoshii Hospital

Tatsumi Chijiwa

Kochi Memorial Hospital

Naoya Sawada

Dohgo Onsen Hospital

\section{Research Article}

Keywords: treat-to-target, disease activity, activities in daily life, quality of life, Boolean remission, time length

Posted Date: April 20th, 2021

DOl: https://doi.org/10.21203/rs.3.rs-431564/v1

License: (c) (i) This work is licensed under a Creative Commons Attribution 4.0 International License. Read Full License 


\section{Abstract}

Importance of time length to achieving clinical remission on disease activity control, daily activities (ADL) and quality of life (QOL) maintenance after the remission was investigated for patients with rheumatoid arthritis (RA).

In patients who achieved remission once or more, relationship between time length from initiation to achieve remission (TL) and patients' background data at baseline, and relationship between TL and mean simplified disease activity score (SDAl), modified Health Assessment Questionnaire Disability Index (HAQ-DI) score, pain score with visual analog scale (PS-VAS), Sharp/van der Heijde Score (SHS) and quality of life score (QOLS) at the first remission and thereafter were evaluated statistically. Patients were divided into two groups whether TL was within 6 months or longer ( $\mathrm{G} \leq 6$ and $\mathrm{G}>6$ ). Change of the parameters and Boolean remission rate (BRR) after the first remission between the two groups were compared statistically.

In 465 patients, TL correlated significantly with the SDAl score, the HAQ score, PS-VAS, SHS, and the QOLS after the remission. The SDAI score and the BRR after the first remission were significantly better in the $G \leq 6$ than in the $G>6$.

TL is an important key to guarantee good disease activity control, ADL and QOL.

\section{Introduction}

There is a broad consensus that clinical remission should be the initial goal for treating rheumatoid arthritis (RA) [1-5], because major of clinical practices and trials reported the benefit of attaining clinical remission on radiographic damage disturbance and daily activity maintenance [6-14]. Clinical remission is indexed with Boolean criteria, simplified disease activity index (SDAI) score [15-17], clinical disease activity index (CDAI) score [17], and 28-joint disease activity score (DAS28) [18]. In clinical practice, sustaining clinical remission is the treatment goal for patients with RA that would improve the radiographic destruction of joints, daily activities in life (ADL), and quality of life (QOL) [19-24]. For these patients, Boolean remission criteria may be the most stringent criteria, and it would guarantee better clinical outcomes for both disease activity and radiographic progression ([22, 25-27].

In contrast, despite the strong recommendation by the European League Against Rheumatism (EULAR) that clinical remission in RA should be achieved within 3-6 months from the first visit a rheumatologist [3-5], the impact of early achievement of clinical remission on clinical outcomes is not discussed enough. Although in literature it is suggested that the early acquisition of clinical remission can achieve better clinical outcomes as a result of a tight disease control [28], it was reported before advocating the treat to target (T2T) strategy. To the best of our knowledge, no studies have reported the impact of early achievement of clinical remission under the T2T strategy. 
Hence, we investigated this issue using a small cohort data; the impact of achieving Boolean remission on clinical outcome was evaluated.

\section{Results}

\section{Parameters and correlation analysis at baseline}

A total of 685 patients were treated under the T2T treating strategy in the institute. Of these, 465 patients had achieved Boolean remission once or more. Out of 465 patients, females comprised $343(73.7 \%)$, and the mean age was 67.8 years(range, from 21-95 years). The mean disease duration at first visit was 6.1 years (range, from 1 months -45 years), and there was no case who demonstrated Boolean remission at the first visit. The mean ACPA titer was $197.4 \mathrm{U} / \mathrm{L}$, and 336 (72.3\%) patients were positive for ACPA. whereas the mean RF titer was $95.2 \mathrm{IU} / \mathrm{mL}$, and 350 (75.3\%) patients were positive for RF. The mean follow up length was 88.1 months (range: 36-122 months; median: 85 months) and mean time length from the first visit to the first Boolean remission was 8.1 months. The mean SDAI score, HAQ score, PSVAS, SHS, and the QOLS at first visit were $13.3,0.467,33.2,47.9$, and 0.834 , respectively. Including these parameters, the mean TJC, SJC, PGA, EGA, and CRP values were shown in Table 1. Among the study parameters, disease duration, HAQ-DI score, PS-VAS, SHS, and QOLS were significantly correlated with the time length by univariate linear regression analysis. In addition, PS-VAS, SHS, and QOLS were significantly correlated with the time length by multivariate linear regression analysis, whereas odds ratios for each parameter were $0.988,0.994$, and 24.789 , respectively (Table 2 ).

\section{Correlation analysis at the first Boolean remission}

For parameters at the first Boolean remission, HAQ-DI score, PS-VAS, SHS, and QOLS demonstrated significant correlation with the time length, whereas SDAI, HAQ-DI score, PS-VAS, SHS, and QOLS after the Boolean remission demonstrated significant correlation with the time length (Table 3).

\section{Comparison analysis}

The comparison between the $G \leq 6$ and the $G>6$ groups revealed that the disease duration, HAQ score, PSVAS, and SHS at baseline in the $G>6$ were significantly higher than that in the $G \leq 6$ group, and QOLS in the $\mathrm{G} \leq 6$ group was significantly higher than that in the $\mathrm{G}>6$ group at baseline (Table 1). Similarly, the HAQ score, SHS, and PS-VAS at the first Boolean remission in the $G>6$ group were significantly higher than that in the $G \leq 6$ group, whereas QOLS in the $G \leq 6$ group demonstrated no significant difference compared with that in the $\mathrm{G}>6$ group. For treatment detail, mean MTX dosage and $b /$ tsDMARD administration rate in the $G>6$ group were significantly higher than those in the $G \leq 6$ group at the first Boolean remission, despite there were no significant difference between the two groups at baseline. The other parameters showed no significant differences between the two groups (Table 4).

The mean value of the SDAI score after the first Boolean remission to last observation demonstrated significant increase than at the first Boolean remission in both groups, and in the $\mathrm{G}>6$ group was 
significantly higher than that in the G $\leq 6$ group. Similarly, the SDAI score, HAQ score, PS-VAS, and SHS after the first Boolean remission to last observation in the $\mathrm{G}>6$ group were also significantly higher than those in the $\mathrm{G} \leq 6$ group, and the mean value of the QOLS in the $\mathrm{G} \leq 6$ group were significantly higher than that in the $\mathrm{G}>6$ group. The Boolean remission rate and SDAl remission rate after the first Boolean remission to last observation were significantly higher in the $G \leq 6$ group than those in the $G>6$ group (Table 4). The change of the SDAI score from the first Boolean remission to after the remission was significantly lower in the $\mathrm{G} \leq 6$ group than that in the $\mathrm{G}>6$ group, whereas the changes in the HAQ-DI score, PS-VAS, SHS, and QOLS demonstrated no significant differences between the two groups (Figure 1).

\section{Correlation between Boolean remission rate and the time length, and other parameters}

A scattered graph of the relationship between total Boolean remission rate and the time length for each case is shown in Figure 2. A most highly correlated approximate equation was exponential equation, and correlation coefficient was 0.5467 . The mean SDAI score, PS-VAS, and SHS demonstrated significant greater values in the group 3 than in the group 2 and group 1, and demonstrated significant greater values in the group 2 than in the RR_60, whereas the mean time length and HAQ score demonstrated significant greater in the group 3 than in the group 2 and group 1 and the mean value of the QOLS demonstrated significant less in the group 3 than in the group 2 and group 1 (Figure 3).

\section{Discussion}

RA is a chronic inflammatory disease that involves the joint structure, and this makes ADL difficult. Therefore, controlling inflammation in the early stage is recommended $[2-5,29]$, because early drug intervention prevents joint destruction due to persistent disease activity and the resulting damage to ADL by controlling disease activity with close monitoring of the objective and subjective disease activity [30]. Although progress in rheumatology has been remarkable, improvement in RA treatment is still the most important issue [31].

Inflammation control is also present in the overarching principle, which is first mentioned in the EULAR recommendation for the managing RA. This leads to the aim of the goal of clinical remission within 3-6 months [3-5].

Indeed, obtaining clinical remission can prevent joint destruction and impairment in ADL, and many studies have reported many facts that progression is prevented by obtaining clinical remission particularly in early RA [32-34]. The importance of the monitoring and recording of the disease activity is much more thorough in a digital era [35]. Disease activity improvement with optimal discriminatory ability was suggested after six months in a clinical trial [36]. A study described the benefit of tight disease control that achieved DAS28 remission significantly earlier compared with conventional treatment for patients with early RA [28]. Tight disease control, namely treatment under T2T strategy, can achieve earlier clinical remission, and it might lead to a more stable clinical course. However, to the best of our knowledge, no study has evaluated the effect of time to remission on the subsequent clinical course in cases with clinical remission using the T2T treatment strategy. 
The high Boolean remission achievement rate in the study was surprising. However, using the real world data, based on the T2T strategy, out of 685 patients during the relatively long follow-up period of $>3$ years, 465 (67.9\%) showed Boolean remission once or more, it is realistic, because patients were picked up from various background. That is different from clinical trial study background. Therefore, it can be considered that such a high rate in both of $G \leq 6$ and $G>6$ groups are realistic given that the Boolean remission achievement rate after the first Boolean remission to last observation was $62.0 \%$ and $43.4 \%$, respectively.

The reason why 6 months is the critical cut off index was as follows. Prior to this study, we preliminarily analyzed in our data for determining cut off index of the time length for the best SDAl course thereafter. The results showed 6 months was the best length as a cut off index (Fig. 4), so we determined 6 months as a critical cut off index in this study.

This study aimed to answer this clinical question. The primary endpoint was the disease activity after remission between the group of patients who achieved Boolean remission within 6 months after the diagnosis of RA and those who required $>6$ months. These results showed that the group who achieved it within 6 months showed significantly better disease activity compared with the group that required $>6$ months. The secondary endpoints of the HAQ-DI score, PS-VAS, SHS, and QOLS also showed significantly superior results. However, above all, these parameters were significantly superior in the group that achieved remission within 6 months even at the baseline, and these differences were maintained throughout the treatment.

In the study, the primary endpoint was set as the SDAI score, but not the DAS28 score. The reason for this was difference of strictness. The remission criteria by means of SDAl is more stringent than of DAS28, so as previously published report a quite different populations were recruited between the Boolean and the DAS28 remission, while similar populations were recruited between the Boolean and the SDAI remission $[26,37]$.

QOL is also an important issue in treating RA, because it directly correlates with work status [38]. Therefore, measuring QOL is important for monitoring disease status in RA treatment, as well as measuring physical function [39]. QOLS is calculated based on EQ-5D, which is a conversion formula applied to each disease in each country. QOLS utilized in the study is used as a reference index when calculating cost-benefit for treating chronic low back pain [40]. To the best of our knowledge, this report is the first to be utilize QOLS to evaluate treatment outcomes in patients with RA, and it showed excellent reproducibility of QOL quantitative evaluation with convenient few questionnaire items and should be considered as a QOL index in patients with RA.

Disease duration and HAQ-DI as patient background factors were also significantly associated with the time length in univariate analysis, similar to Aletaha et al. study [34], but PS-VAS, SHS, and QOLS were shown to be associated by multivariate analysis. These three parameters showed significant differences even at baseline, at the first Boolean remission, and after the first Boolean remission in comparison between the two groups, and the results strongly suggest that these factors correlated with the time 
length. However, these factors did not show any difference between the two groups regarding the change after the acquisition of Boolean remission, and the parameters that were affected by time length were SDAI remission rate, Boolean remission rate, and disease activity control after the achievement of Boolean remission. It is presumed that the significant difference in HAQ-DI and Boolean remission after the acquisition of at the first Boolean remission was because many cases with higher treatment resistance were included in the $G>6$ group.

MTX dose and b/tsDMARD administration rate were significantly higher in the $\mathrm{G}>6$ group, despite these parameters demonstrated no significant difference between the two groups at baseline. This may be because the goal of Boolean remission resulted in the need for more intensive treatment compared with the $\mathrm{G} \leq 6$ group. However, patient's drug adherence was not considered in the study. There is a wide variability of drug adherence in patients, which strongly influences clinical results (41). Previous treatment including b/tsDMARD administration at baseline did not influenced on the time length. Like these, treatment initiation before disease activity gets high may have no influence on the time length, because no disease activity difference at baseline demonstrated between the two groups. Treatment protocol in the study was commonly designed under the T2T strategy, so every patient recruited in the study accepted shared decision making and had been treated targeted clinical remission. It seems to be clear that patient related outcomes (PRO) such as PS-VAS and QOLS, is rather important for obtaining shorter time length. These parameters and the SHS score throughout treating from baseline to after the first Boolean remission acquisition demonstrated significant correlation with the time length. These results suggested that patient who have good PROs from the baseline is well responsible to treatment when tight disease control is targeted.

Even acquisition of Boolean remission, sustaining the remission is obviously important. The only temporary achievement of Boolean remission is more inferior than sustaining Boolean remission. The results of relationship between the Boolean remission rate and other parameters demonstrated the lower remission rate group demonstrated more inferior in every parameter, while the lower remission rate group also demonstrated significantly longer time length than the two higher remission rate groups. These results suggested that the time length reflected more sensitive in clinical outcomes including disease activity control and PRO.

Overall, the validity of aiming for clinical remission within 3-6 months under the T2T strategy has been shown to be effective. The strategy leads to the maintenance of disease activity as well as disease control. This in turn appeared to correlate with the maintenance of ADL and prevention of altered QOL. However, it is conceivable that achieving Boolean remission leads to maintenance. These prospects have not yet been proven in the study and require further investigation.

There are some limitations to the study. This was a single institutional study in which no ethnic and gender considerations were set and the influence of subjective comorbidities, such as depression, anxiety, fatigue, fibromyalgia, and other diseases were not considered [36]. However, this study addresses the effect of time length from the initiation of treatment to achieve Boolean remission for patients with RA. 
In conclusion, we have investigated the impact of time length from baseline to achieve Boolean remission on disease activity control, $\mathrm{ADL}$ and QOL maintenance with a cohort study. Results demonstrated that the shorter period to achieve the remission, the tighter disease activity is controlled and the better ADL and QOL are maintained. Six months may be the key to guarantee more stable clinical course after acquirement of Boolean remission.

\section{Methods}

\section{Treatment protocol}

We have treated RA patients with RA since August 2010 under the T2T strategy in accordance with the EULAR recommendations in the institute where the only specialized clinic for rheumatic diseases in the community. All patients met the American College of Rheumatology/EULAR (ACR/EULAR) classification criteria [42[ at the initiation of RA treatment in the institute.

Patients were consulted and treated every from every 2-3 months since the diagnosis of RA. They were monitored for their tenderness joint count (TJC), swollen joint count (SJC), patient's global assessment (PGA), evaluator's global assessment (EGA), C-reactive protein (CRP), and disease activity indices, such as CDAI, SDAI, DAS28, and Boolean criteria at every visit to the institute. Health Assessment Questionnaire Disability Index (HAQ-DI) score [43], pain score using visual analog scale (PS-VAS), and EuroQOL-5 ${ }^{\text {th }}$ dimension-5L (EQ-5D) [44] were also monitored, and the quality of life score (QOLS) calculated from EQ-5D [45] was determined at every visit from the time of diagnosis (baseline). As an index of joint damage caused by RA, Sharp/van der Heijde score (SHS) [46] was measured using X-ray pictures at the time of diagnosis and every other year, and within three months after achievement of first Boolean remission. SHS was confirmed by two physicians.

\section{Patient and parameters selection, and correlation analysis at baseline}

In patients who had been treated under T2T strategy, We enrolled the patients who had achieved Boolean remission once or more, and were consecutively followed up for $>3$ years, in the study. Time length from the first visit to first Boolean remission was calculated. The relationship between the time length and each of background parameters such as sex, age, disease duration of RA, SHS at first visit, anti-cyclic citrullinated peptide antibodies (ACPA), rheumatoid factor (RF), TJC, SJC, PGA, EGA, CRP, SDAI, HAQ, PSVAS, SHS, and QOLS were evaluated statistically using univariate linear regression analysis, and then multivariate linear regression analysis was performed to evaluate the relationship between the time length and the parameters that demonstrated significant correlation in the univariate model.

\section{Correlation analysis at the first Boolean remission}

The relationship between the time length and each of the mean values of the SDAI score, HAQ score, PSVAS, SHS, and QOLS at the first Boolean remission and thereafter was then evaluated using univariate linear regression analysis considering each parameter as a dependent factor and the time length as an 
independent factor, and odds ratio for time length to attain Boolean remission with 6 months or less regarding these parameters, which demonstrated significant correlation using multivariate model linear regression analysis, was evaluated using binary logistic regression analysis.

\section{Comparison analysis}

Patients were subsequently divided into the $G \leq 6$ and $G>6$ groups based on the time length for achievement of first Boolean remission within two groups: $G \leq 6$, a patient group who attained Boolean remission within 6 months from the first visit; $G>6$, a patient group who attained Boolean remission more than 6 months from the first visit. The two groups were compared with regard to the SDAI score, HAQ score, PS-VAS, SHS, and QOLS at first visit and at the time of first Boolean remission, and the mean values of these parameters after remission were evaluated using the Mann-Whitney $U$ test. Methotrexate (MTX), biologic/targeted disease-modifying anti-rheumatic drug (b/tsDMARD), and glucocorticoid steroid (GCS) administration rate at first visit were also compared in between the two groups using MannWhitney U-test. Moreover, changes of these parameters from the first Boolean remission to thereafter between the two groups were also compared using the Mann-Whitney $U$ test. Rates of treatment with mean doses of $b / t s D M A R D, M T X$, and GCS administration rate and mean dose of administration at the first Boolean remission and thereafter between the two groups were also compared using the MannWhitney $U$ and chi square tests. The mean Boolean remission rate after the first remission, and SDAI remission rate at the first Boolean remission and thereafter were also compared between the two groups using the Mann-Whitney $U$ test. The primary endpoint was the mean value of the SDAl score after the first Boolean remission to last observation, and secondary endpoints included the mean values of the HAQ score, PS-VAS, SHS, and QOLS after the first Boolean remission.

\section{Correlation between Boolean remission rate and the time length, and other parameters}

A relationship between total Boolean remission rate and the time length for each case was plotted with scattered graph and evaluated with approximate curve equation, and the relationship was evaluated using linear regression analysis. Based on the equation, patients were classified into three groups according to Boolean remission rate; 1 , a patient group whose Boolean remission rate was $60 \%$ or more ; 2 , a patient group whose Boolean remission rate was less than $60 \%$ and $30 \%$ or more; 3 , a patient group whose Boolean remission rate was less than $30 \%$. Mean values of the time length, SDAl, HAQ-DI, PS-VAS, SHS, and QOS of these three groups were compared using T-test.

The study protocol was approved by the ethics committee of the study institution (approval number: Y2020-RA-2). All methods were performed in accordance with the Declaration of Helsinki and other relevant guidelines and regulations.

\section{Software used in the statistical procedures}

All the statistical procedures were performed using StatPlus:mac ${ }^{\circledR}$ (AnalystSoft, Inc., Walnut, CA, USA), and significance level was set within $5 \%$. 


\section{List Of Abbreviations}

RA, rheumatoid arthritis ; SDAl, simplified disease activity index ; CDAl, clinical disease activity index ; DAS28, 28-joint disease activity score ; ADL, daily activities in life ; QOL, quality of life ; EULAR, the European League Against Rheumatism ; T2T, treat to target ; TJC, tenderness joint count ; SJC, swollen joint count ; PGA, patient's global assessment ; EGA, evaluator's global assessment ; CRP, C-reactive protein ; HAQ-DI, Health Assessment Questionnaire Disability Index ; PS-VAS, pain score using visual analog scale ; EQ-5D, EuroQOL-5 ${ }^{\text {th }}$ dimension-5L ; QOLS, quality of life score ; SHS, Sharp/van der Heijde score ; ACPA, anti-cyclic citrullinated peptide antibodies ; RF, rheumatoid factor ; b/tsDMARD, biologic/targeted synthetic disease-modifying anti-rheumatic drug ; MTX, methotrexate ; GCS, glucocorticoid steroid ; PRO, patient related outcomes.

\section{Declarations}

\section{Acknowledgment}

The authors would like to thank Kaoru Kuwabara, Sayori Masuoka, Eri Morichika, and Aoi Yoshida for their dedicated data collection.

\section{Author contributions}

IY wrote manuscript

TC gave numerous data

NS also gave data used in the study.

All authors have read the manuscript and agreed with the content.

\section{Conflict of interest statement}

None of author and his families have share income, property with any person, or any grants or other financial supports of the study.

\section{Funding statement}

Not applicable.

\section{Ethics and consent}

The study protocols and patient consent requirements were approved by Yoshii Hospital Ethics Committee (approval number: Y-2020-RA-2). The subjects and their families were informed that the personal information obtained in this study was anonymous and would only be used for analysis. 
Informed consent was obtained from all participants enrolled in the study and all subjects and their families provided signed consent.

\section{Consent for publication}

Not applicable

\section{Availability of data and material}

The datasets used and/or analyzed during the current study are available from the corresponding author on reasonable request.

\section{References}

1. Makinen, H., Hannonen, P. \& Sokka, T. Definitions of remission for rheumatoid arthritis and review of selected clinical cohorts and randomized clinical trials for the case of remission. Clin Exp Rheumatol 24: S22-S28 (2006).

2. Smolen, J. S., et al. Treating rheumatoid arthritis to target: recommendations of an international task force. Ann Rheum Dis 69: 631-637 (2010).

3. Smolen, J. S., et al. Treating rheumatoid arthritis to target: 2014 update of the recommendations of an international task force. Ann Rheum Dis 75: 3-15 (2016).

4. Smolen, J. S., et al. EULAR recommendations for the management of rheumatoid arthritis with synthetic and biological disease-modifying antirheumatic drugs: 2016 update. Ann Rheum Dis 76: 960-977 (2017).

5. Smolen, J. S., et al. EULAR recommendations for the management of rheumatoid arthritis with synthetic and biological disease-modifying antirheumatic drugs: 2016 update. Ann Rheum Dis 79: 685-699 (2020).

6. van der Heijde, D. $M$, et al. Prognostic factors for radiographic damage and physical disability in early rheumatoid arthritis. A prospective follow-up study of 147 patients. Br J Rheumato/ 31: 519525 (1992).

7. van Leeuwen, M. A., et al. Interrelationship of outcome measures and process variables in early rheumatoid arthritis. A comparison of radiologic damage, physical disability, joint counts, and acute phase reactants. J Rheumato/ 21: 425-429 (1994).

8. Drossaers-Bakker, K. W., et al. Long-term course and outcome of functional capacity in rheumatoid arthritis: the effect of disease activity and radiologic damage over time. Arthritis Rheum 42: 18541860 (1999).

9. Welsing, M. J., et al. The relationship between disease activity and radiologic progression in patients with rheumatoid arthritis: a longitudinal analysis. Arthritis Rheum 50: 2082-2093 (2004).

10. Aletaha, D., et al. Remission and active disease in rheumatoid arthritis: defining criteria for disease activity states. Arthritis Rheum 52: 2625-2636 (2005). 
11. Smolen, J. S., et al. Predictors of joint damage in patients with early rheumatoid arthritis treated with high-dose methotrexate with or without concomitant infliximab: results from the ASPIRE trial. Arthritis Rheum 54: 702-710 (2006).

12. Smolen, J. S., Aletaha, D., Koeller, M., Weisman, M. H., Emery, P. New therapies for treatment of rheumatoid arthritis. Lancet 370: 1861-1874 (2007).

13. Smolen, J. S., et al. Radiographic changes in rheumatoid arthritis patients attaining different disease activity states with methotrexate monotherapy and infliximab plus methotrexate: the impacts of remission and tumour necrosis factor blockade. Ann Rheum Dis 68: 823-827 (2009).

14. Schoels, M., et al. Evidence for treating rheumatoid arthritis to target: results of a systematic literature search. Ann Rheum Dis 69: 638-643 (2010).

15. Smolen, J. S., et al. A simplified disease activity index for rheumatoid arthritis for use in clinical practice. Rheumatology (Oxford) 42: 244-257 (2003).

16. Aletaha, D., et al. Remission and active disease in rheumatoid arthritis: defining criteria for disease activity states. Arthritis Rheum 52: 2625-2636 (2005).

17. Aletaha, D. \& Smolen, J. S. The Simplified Disease Activity Index (SDAI) and Clinical Disease Activity Index (CDAl) to monitor patients in standard clinical care. Best Pract Res Clin Rheumato/ 21: 663-675 (2007).

18. Prevoo, N. L., et al. Modified disease activity scores that include twenty-eight-joint counts. Development and validation in a prospective longitudinal study of patients with rheumatoid arthritis. Arthritis Rheum 38: 44-48 (1995).

19. Molenaar, E. T. H., et al. Progression of radiologic damage in patients with rheumatoid arthritis in clinical remission. Arthritis Rheumatism 50: 36-42 (2004).

20. Mieray, M., et al. Assessing remission in clinical practice. Rheumatology (Oxford) 46: 975-979 (2007).

21. Aletaha, D., et al. Rheumatoid arthritis joint progression in sustained remission is determined by disease activity levels preceding the period of radiographic assessment. Arthritis Rheumatism 60: 1242-1249 (2009).

22. Felson, D. T., et al. American College of Rheumatology/European League against Rheumatism preliminary definition of remission in rheumatoid arthritis for clinical trials. Arthritis Rheumatism 63; 573-586 (2011).

23. Tanaka, Y., et al. The effect of deep or sustained remission on maintenance of remission after dose reduction or withdrawal of etanercept in patients with rheumatoid arthritis. Arthritis Res Ther 21: 164 (2019).

24. Sundlisæter, N. P., et al. Predictors of sustained remission in patients with early rheumatoid arthritis treated according to an aggressive treat-to-target protocol. Rheumatology (Oxford) 57: 2022-2031 (2018).

25. Yilmaz-Oner, S., et al. Predictors and the optimal duration of sustained remission in rheumatoid arthritis. Clin Rheumato/ 38: 3033-3039 (2019). 
26. Aletaha, D., et al. Differences in disease activity measures in patients with rheumatoid arthritis who achieved DAS, SDAl, or CDAl remission but not Boolean remission. Semin Arthritis Rheum 50: 276284 (2020).

27. Studenic, P., et al. Testing different thresholds for patient global assessment in defining remission for rheumatoid arthritis: are the current ACR/EULAR Boolean criteria optimal?. Ann Rheum Dis 79: 445452 (2020).

28. Schipper, L. G,. et al. A tight control treatment strategy aiming for remission in early rheumatoid arthritis is more effective than usual care treatment in daily clinical practice: a study of two cohorts in the Dutch Rheumatoid Arthritis Monitoring registry. Ann Rheum Dis 71: 845-850 (2012).

29. Nell, V. P. K., et al. Benefit of very early referral and very early therapy with disease-modifying antirheumatic drugs in patients with early rheumatoid arthritis. Rheumatology 43: 906-914 (2004).

30. Aletaha, D., Funovits, J. \& Smolen, J. S. The importance of reporting disease activity states in rheumatoid arthritis clinical trials. Arthritis Rheumatism 58: 2622-2631 (2008).

31. Burmester, G. R., Bijlsma, J. W. J., Cutolo, M. \& Mclnnes, I. B. Managing rheumatic and musculoskeletal diseases - past, present and future. Nat Rev Rheumatol 13: 443-448 (2017).

32. Vastesaeger, N., Xu, S., Aletaha, D., St. Clair, E.W. \& Smolen, J. S. A pilot risk model for prediction of rapid radiographic progression in rheumatoid arthritis. Rheumatology 48: 1114-1121 (2009).

33. Choy, T., et al. Physician global assessment at 3 months is strongly predictive of remission at 12 months in early rheumatoid arthritis: results from the CATCH cohort. Rheumatology 53: 482-490 (2014).

34. Aletaha, D., et al. Effect of disease duration and prior disease-modifying antirheumatic drug use on treatment outcomes in patients with rheumatoid arthritis. Ann Rheum Dis 78: 1609-1615 (2019).

35. Aletaha, D., Bécède, M. \& Smolen, J. S. Information technology concerning SDAI and CDAI. Clin Exp Rheumatol 34: S45-S48 (2016).

36. Smolen, J. S., et al. Disease activity improvements with optimal discriminatory ability between treatment arms: applicability in early and established rheumatoid arthritis clinical trials. Arthritis Res Ther 21: 231 (2019).

37. Yoshii, I. Attaining CDAI remission is the first gateway to attain Boolean remission. Semin Arthritis Rheum 50: 624-626 (2020).

38. Grønning, K., Rødevand, E. \& Steinsbekk, A. Paid work is associated with improved health-related quality of life in patients with rheumatoid arthritis. Clin Rheumatol 29: 1317-1322 (2010).

39. Aletaha, D., Smolen, J. S. \& Ward, M. M. Measuring function in rheumatoid arthritis. Arthritis Rheumatism 54: 2784-2792 (2006).

40. Igarashi, A., et al. Cost-effectiveness analysis of pregabalin for treatment of chronic low back pain in patients with accompanying lower limb pain (neuropathic component) in Japan. Clinicoecon Outcomes Res 7: 505-520 (2015). 
41. Studenic, P. \& Aletaha, D. The slippery road of adherence in chronically ill individuals. Rheumatology 59: 9-11 (2020).

42. Inanc, N., Yilmaz-Oner, S., Can, M., Sokka, T. \& Direskeneli, H. The role of depression, anxiety, fatigue, and fibromyalgia on the evaluation of the remission status in patients with rheumatoid arthritis. $J$ Rheumatol 41: 1755-1760 (2014).

43. Aletaha, D., et al. 2010 Rheumatoid arthritis classification criteria: an American College of Rheumatology/European League Against Rheumatism collaborative initiative. Arthritis Rheum 62:2569-2581 (2010).

44. Welsing, P. M., van Gestel, A. M., Swinkels, H. K., Kiemeney, L. A. \& van Riel, P. L. The relationship between disease activity, joint destruction, and functional capacity over the course of rheumatoid arthritis. Arthritis Rheum 44: 2009-2017 (2001).

45. Rabin, R. \& de Charro, F. EQ-5D: a measure of health status from the EuroQol. Ann Med 33: 337-343 (2001).

46. van der Heijde, D. M., van Riel, P. L., Nuver-Zwart, I. H., Gribnau, F. W. \& van de Putte, L. B. Effects of hydroxychloroquine and sulphasalazine on progression of joint damage in rheumatoid arthritis. Lancet 8646: 1036-1038 (1989).

\section{Tables}


Table 1

Demographic and clinical characteristics of the patient and each group at baseline

\begin{tabular}{|c|c|c|c|c|}
\hline & in all & $\mathrm{G} \leq 6$ & $G>6$ & $p$-value \\
\hline Cases & 465 & 323 & 142 & \\
\hline Female (\%) & $343(73.7 \%)$ & $245(76.8 \%)$ & $98(69.0 \%)$ & $1.2 \times 10^{-1}$ \\
\hline age & $67.8,13.9,21-95$ & $67.6,14.1,25-95$ & $68.2,13.4,21-93$ & $8.1 \times 10^{-1}$ \\
\hline $\begin{array}{l}\text { disease } \\
\text { duration }\end{array}$ & $6.1,7.9,0.1-45$ & $5.4,7.5,0.1-45$ & $7.7,8.6,0.1-45$ & $9.2 \times 10^{-4}$ \\
\hline $\begin{array}{l}\text { ACPA positive } \\
(\%)\end{array}$ & $336(72.3 \%)$ & $232(71.8 \%)$ & $104(73.2 \%)$ & $7.5 \times 10^{-1}$ \\
\hline $\begin{array}{l}\text { RF positive } \\
(\%)\end{array}$ & $350(75.3 \%)$ & $243(75.2 \%)$ & $107(75.4 \%)$ & $9.8 \times 10^{-1}$ \\
\hline MTX use & $254(54.6 \%)$ & $180(55.7 \%)$ & $74(52.1 \%)$ & $5.4 \times 10^{-1}$ \\
\hline $\begin{array}{l}\mathrm{b} / \mathrm{tsDMARD} \\
\text { use }\end{array}$ & 44 (9.5\%) & $23(7.1 \%)$ & 21 (14.8\%) & $1.8 \times 10^{-1}$ \\
\hline GCS use & $128(27.5 \%)$ & $81(25.1 \%)$ & $47(33.1 \%)$ & $2.1 \times 10^{-1}$ \\
\hline TJC & $2.3,3.0,0-20$ & $2.2,3.1,0-20$ & $2.5,2.9,0-19$ & $3.0 \times 10^{-2}$ \\
\hline SJC & $3.9,4.8,0-28$ & $4.0,5.2,0-28$ & $3.8,4.8,0-16$ & $2.4 \times 10^{-1}$ \\
\hline PGA & $2.9,2.8,0-10$ & $2.8,2.9,0-10$ & $3.3,2.7,0-10$ & $2.1 \times 10^{-2}$ \\
\hline EGA & $2.2,2.1,0-10$ & $2.1,2.1,0-10$ & $2.3,1.9,0-10$ & $1.6 \times 10^{-1}$ \\
\hline CRP & $14.0,27.0,0-207.0$ & $15.0,29.0,0-207.0$ & $14.0,22.0,0-144.0$ & $2.5 \times 10^{-1}$ \\
\hline DAS28 & $3.9,1.2,2.6-6.4$ & $3.8,1.2,2.6-6.4$ & $3.9,1.0,2.6-5.5$ & $1.3 \times 10^{-1}$ \\
\hline CDAl & $11.8,10.5,4-66$ & $11.8,11.3,7-66$ & $11.9,8.6,4-56$ & $4.5 \times 10^{-1}$ \\
\hline SDAI & $13.3,12.2,4.3-71.1$ & $13.3,12.9,7.4-71.1$ & $13.3,9.8,4.3-64.4$ & $6.8 \times 10^{-1}$ \\
\hline HAQ-DI & $0.467,0.582,0-2.75$ & $0.418,0.564,0-2.75$ & $\begin{array}{l}0.578,0.607,0- \\
2.625\end{array}$ & $9.1 \times 10^{-3}$ \\
\hline PS-VAS & $33.2,29.5,0-100$ & $30.3,28.9,0-100$ & $40.5,29.6,0-100$ & $2.2 \times 10^{-4}$ \\
\hline SHS & $47.9,62.9,0-340$ & $28.3,51.3,0-296$ & $69.1,78.9,0-340$ & $2.0 \times 10^{-5}$ \\
\hline QOLS & $\begin{array}{l}0.834,0.124,0.188- \\
0.939\end{array}$ & $\begin{array}{l}0.847,0.131,0.188- \\
0.939\end{array}$ & $\begin{array}{l}0.805,0.113,0.586- \\
0.939\end{array}$ & $7.6 \times 10^{-8}$ \\
\hline
\end{tabular}

Units: age, year old ; disease duration, years ; CRP, mg/l ; PS-VAS, millimeter. The other parameters' 
units are numerical values.

Except Female, ACPA positive, and RF positive, mean value, standard deviation, and range separated with comma are shown. In Female, ACPA positive, and RF positive, real numbers and their ratios in the parentheses are shown.

In Female, ACPA positive, and RF positive, $p$-values were calculated using chi square test, while in the other parameters, Mann-Whitney U-test for the statistical comparison between the $G \leq 6$ and the $G>6$ was used.

Statistically significant columns are shown in bold style. 
Table 2

Relationship between the time length from the baseline to the first Boolean remission and parameters at the baseline

\begin{tabular}{|c|c|c|c|c|c|}
\hline \multirow[b]{2}{*}{ parameters } & \multicolumn{2}{|c|}{ univariate model } & \multicolumn{2}{|c|}{ multivariate model } & \multirow{2}{*}{$\begin{array}{l}\text { Binary logistic regression } \\
\text { analysis } \\
\text { Odds ratio }\end{array}$} \\
\hline & $95 \% \mathrm{Cl}$ & $p$-value & $95 \% \mathrm{Cl}$ & $p$-value & \\
\hline age & $\begin{array}{l}-0.053- \\
0.120\end{array}$ & $4.5 \times 10^{-1}$ & & & \\
\hline ACPA & $\begin{array}{l}-0.002- \\
0.003\end{array}$ & $8.0 \times 10^{-1}$ & & & \\
\hline $\mathrm{RF}$ & $\begin{array}{l}-0.004- \\
0.006\end{array}$ & $6.1 \times 10^{-1}$ & & & \\
\hline $\begin{array}{l}\text { disease } \\
\text { duration }\end{array}$ & $\begin{array}{l}0.026- \\
0.336\end{array}$ & $2.2 \times 10^{-2}$ & $\begin{array}{l}-0.229- \\
0.365\end{array}$ & $6.5 \times 10^{-1}$ & 0.967 \\
\hline TJC & $\begin{array}{l}-0.218- \\
0.598\end{array}$ & $3.5 \times 10^{-1}$ & & & \\
\hline SJC & $\begin{array}{l}-0.265- \\
0.251\end{array}$ & $9.6 \times 10^{-1}$ & & & \\
\hline PGA & $\begin{array}{l}-0.041- \\
0.835\end{array}$ & $7.6 \times 10^{-2}$ & & & \\
\hline EGA & $\begin{array}{l}-0.945- \\
0.989\end{array}$ & $9.6 \times 10^{-1}$ & & & \\
\hline CRP & $\begin{array}{l}-0.531- \\
0.372\end{array}$ & $7.3 \times 10^{-1}$ & & & \\
\hline DAS28 & $\begin{array}{l}-0.475- \\
1.609\end{array}$ & $2.9 \times 10^{-1}$ & & & \\
\hline CDAI & $\begin{array}{l}-0.062- \\
0.171\end{array}$ & $3.6 \times 10^{-1}$ & & & \\
\hline SDAI & $\begin{array}{l}-0.068- \\
0.133\end{array}$ & $5.3 \times 10^{-1}$ & & & \\
\hline HAQ-DI & $\begin{array}{l}0.596- \\
4.796\end{array}$ & $1.2 \times 10^{-2}$ & $\begin{array}{l}-5.504- \\
1.351\end{array}$ & $2.3 \times 10^{-1}$ & 0.999 \\
\hline PS-VAS & $\begin{array}{l}0.023- \\
0.104\end{array}$ & $2.2 \times 10^{-3}$ & $\begin{array}{l}0.034- \\
0.159\end{array}$ & $2.5 \times 10^{-3}$ & 0.988 \\
\hline SHS & $\begin{array}{l}0.031- \\
0.072\end{array}$ & $1.1 \times 10^{-6}$ & $\begin{array}{l}0.030- \\
0.091\end{array}$ & $1.4 \times 10^{-4}$ & 0.994 \\
\hline QOLS & $\begin{array}{l}-31.55- \\
-8.03\end{array}$ & $1.0 \times 10^{-3}$ & $\begin{array}{l}-42.049- \\
-9.938\end{array}$ & $1.6 \times 10^{-4}$ & 24.789 \\
\hline
\end{tabular}


defined as dependent factor and the parameters were defined as independent factors, and then multivariate linear regression analysis was performed with the parameters that demonstrated significant correlation with the univariate model.

Statistically significant columns are shown in bold style.

Table 3

Correlation of the time length with clinical parameters at the First Boolean remission and with mean value of parameters thereafter

\begin{tabular}{|c|c|c|c|c|}
\hline & \multicolumn{2}{|c|}{ at the first Boolean remission } & \multicolumn{2}{|c|}{ after the First Boolean remission } \\
\hline parameters & $95 \% \mathrm{Cl}$ & $p$-value & $95 \% \mathrm{Cl}$ & $p$-value \\
\hline SDAl & $-0.005-0.008$ & $7.6 \times 10^{-1}$ & $0.023-0.059$ & $8.0 \times 10^{-6}$ \\
\hline HAQ-DI & $0.005-0.013$ & $5.6 \times 10^{-6}$ & $0.006-0.013$ & $6.7 \times 10^{-7}$ \\
\hline PS-VAS & $0.061-0.348$ & $5.4 \times 10^{-3}$ & $0.100-0.317$ & $2.1 \times 10^{-4}$ \\
\hline SHS & $0.670-1.436$ & $1.4 \times 10^{-7}$ & $1.023-2.144$ & $5.5 \times 10^{-8}$ \\
\hline QOLS & $-0.003--0.001$ & $4.0 \times 10^{-4}$ & $-0.003--0.001$ & $5.1 \times 10^{8}$ \\
\hline
\end{tabular}


Comparison of parameters at the first Boolean remission and mean values of parameter thereafter between the $\mathrm{G} \leq 6$ and the $\mathrm{G}>6$

\begin{tabular}{|c|c|c|c|c|c|c|}
\hline & \multicolumn{3}{|c|}{ at the first Boolean remission } & \multicolumn{3}{|c|}{$\begin{array}{l}\text { after the first Boolean remission to } \\
\text { last observation }\end{array}$} \\
\hline & $\mathrm{G} \leq 6$ & $\mathrm{G}>6$ & $p$-value & $\mathrm{G} \leq 6$ & $\mathrm{G}>6$ & $p$-value \\
\hline time length & $2.7,1.6$ & $18.7,8.1$ & $<1.0 \times 10^{-10}$ & $84.6,42.3$ & $71.3,35.8$ & $1.1 \times 10^{-2}$ \\
\hline $\begin{array}{l}\text { MTX administration } \\
\text { rate }\end{array}$ & $70.3 \%$ & $66.9 \%$ & $4.7 \times 10^{-1}$ & $77.5 \%$ & $70.4 \%$ & $1.0 \times 10^{-1}$ \\
\hline mean MTX dosage & 7.9 & 8.8 & $1.2 \times 10^{-2}$ & 8.2 & 8.3 & $8.4 \times 10^{-1}$ \\
\hline $\begin{array}{l}\text { GCS administration } \\
\text { rate }\end{array}$ & $29.4 \%$ & $27.5 \%$ & $6.7 \times 10^{-1}$ & $29.6 \%$ & $43.7 \%$ & $2.4 \times 10^{-1}$ \\
\hline mean GCS dosage & 3.2 & 3.3 & $8.6 \times 10^{-1}$ & 3.3 & 3.9 & $3.0 \times 10^{-1}$ \\
\hline $\begin{array}{l}\mathrm{b} / \mathrm{tsDMARD} \\
\text { administration rate }\end{array}$ & $13.3 \%$ & $27.5 \%$ & $2.4 \times 10^{-4}$ & $19.3 \%$ & $20.4 \%$ & $7.8 \times 10-1$ \\
\hline SDAI & $\begin{array}{l}1.03 \\
1.04\end{array}$ & $\begin{array}{l}1.10 \\
1.00\end{array}$ & $4.9 \times 10^{-1}$ & $2.91,2.40$ & $4.05,3.03$ & $2.0 \times 10^{-5}$ \\
\hline SDAI remission rate & $96.5 \%$ & $96.5 \%$ & $9.8 \times 10^{-1}$ & $72.2 \%$ & $58.0 \%$ & $1.2 \times 10^{-4}$ \\
\hline Boolean remission rate & $100 \%$ & $100 \%$ & $1.0 \times 10^{-0}$ & $62.0 \%$ & $43.4 \%$ & $<1.0 \times 10^{-10}$ \\
\hline HAQ-DI & $\begin{array}{l}0.370 \\
0.551\end{array}$ & $\begin{array}{l}0.552 \\
0.600\end{array}$ & $1.8 \times 10^{-3}$ & $\begin{array}{l}0.364 \\
0.510\end{array}$ & $\begin{array}{l}0.567 \\
0.599\end{array}$ & $2.3 \times 10^{-4}$ \\
\hline PS-VAS & $\begin{array}{l}\text { 13.0, } \\
18.4\end{array}$ & $\begin{array}{l}20.7 \\
24.5\end{array}$ & $2.1 \times 10^{-4}$ & $17.7,14.9$ & $24.1,17.7$ & $6.0 \times 10^{-5}$ \\
\hline SHS & $\begin{array}{l}27.3 \\
49.8\end{array}$ & $\begin{array}{l}70.7 \\
79.5\end{array}$ & $9.0 \times 10^{-5}$ & $26.5,48.6$ & $69.0,77.8$ & $3.7 \times 10^{-6}$ \\
\hline QOLS & $\begin{array}{l}0.845 \\
0.139\end{array}$ & $\begin{array}{l}0.791 \\
0.156\end{array}$ & $7.9 \times 10^{-2}$ & $\begin{array}{l}0.828, \\
0.108\end{array}$ & $\begin{array}{l}0.765 \\
0.128\end{array}$ & $7.0 \times 10^{-5}$ \\
\hline
\end{tabular}

Units: time length, months; MTX dosage, mg per week ; mean GCS dosage, mg per day ; PS-VAS,

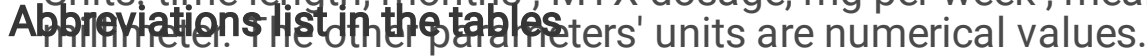

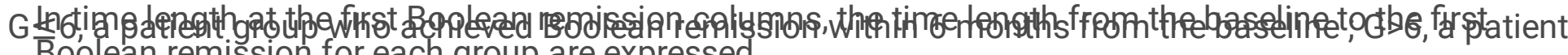
Boolean remisssion for each group are expressed. group who achieved Boolean remission longer than 6 months from the baseline; ACPA, anti-cyclic

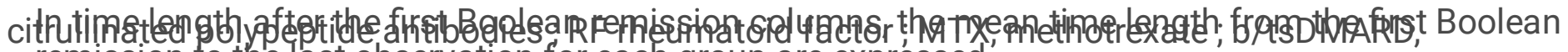
remission to the ast observation for each group are expressed. biologic/targeted disease-modifying anti-rheumatic drug; GCS, glucocorticoid steroid ; TJC, tenderness

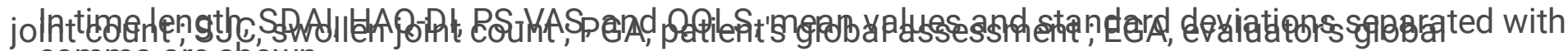
comma are shown. assessment; CRP, C-reactive protein, DAS28, 28-joints disease activity score, CDAl, clinical disease

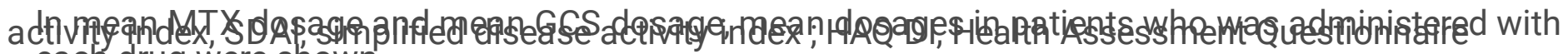
each drug were shown. 


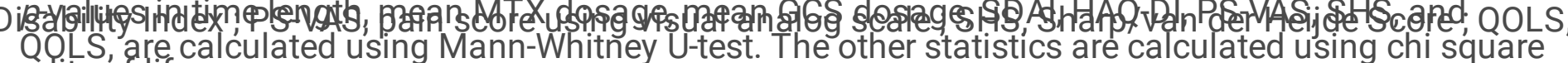
questy of life score.

Statistically significant columns are shown in bold style.

Figures
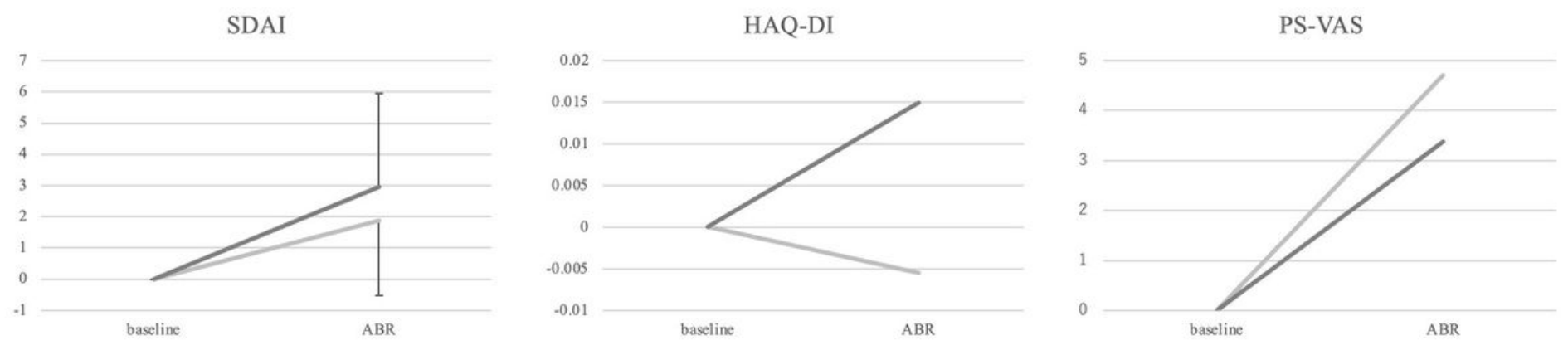

SHS
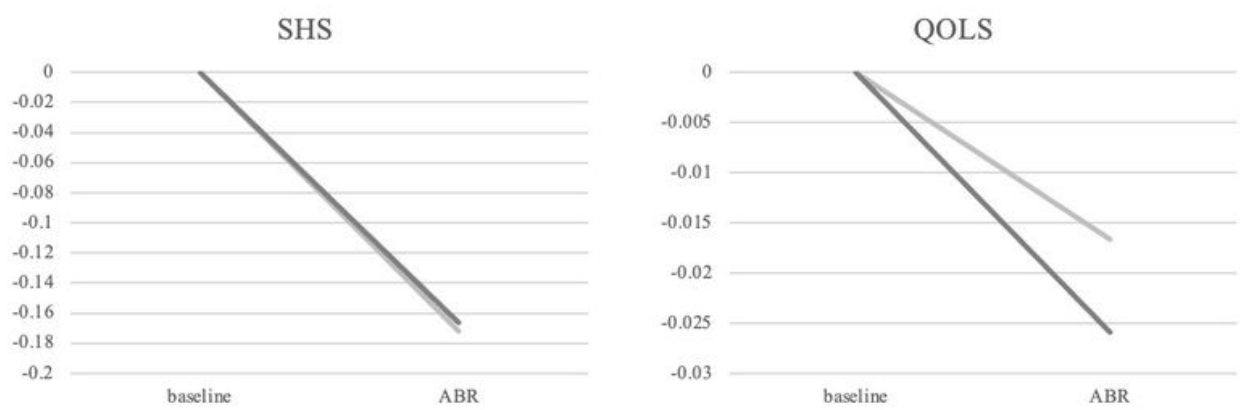

Figure 1

\section{Figure 1}

Changes of the parameters from the first Boolean remission to after the remission (ABR) comparing in the $G \leq 6$ and in the $G>6$. Change of mean SDAl score demonstrated significantly higher in the $G>6$ than in the $\mathrm{G} \leq 6$ (p-value: $5.0 \times 10-5$ ), whereas change of the other parameters such as HAQ-DI, PS-VAS, SHS, and QOLS demonstrated no significant difference between the two groups. 


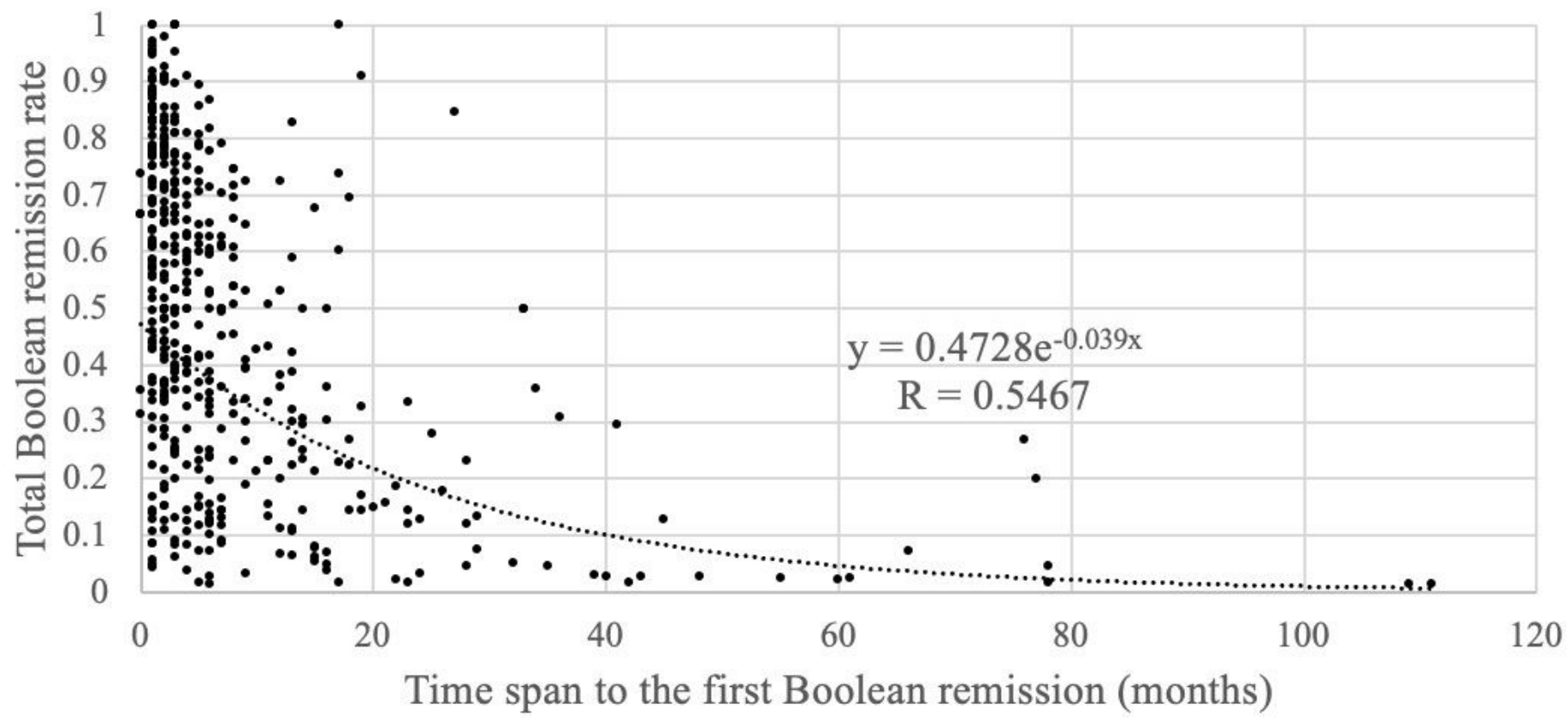

Figure 2

Figure 2

Relationship between total Boolean remission rate (Y-axis) and time length to the first Boolean remission (X-axis). An approximate equation was exponential equation, and correlation coefficient was 0.5467 . 

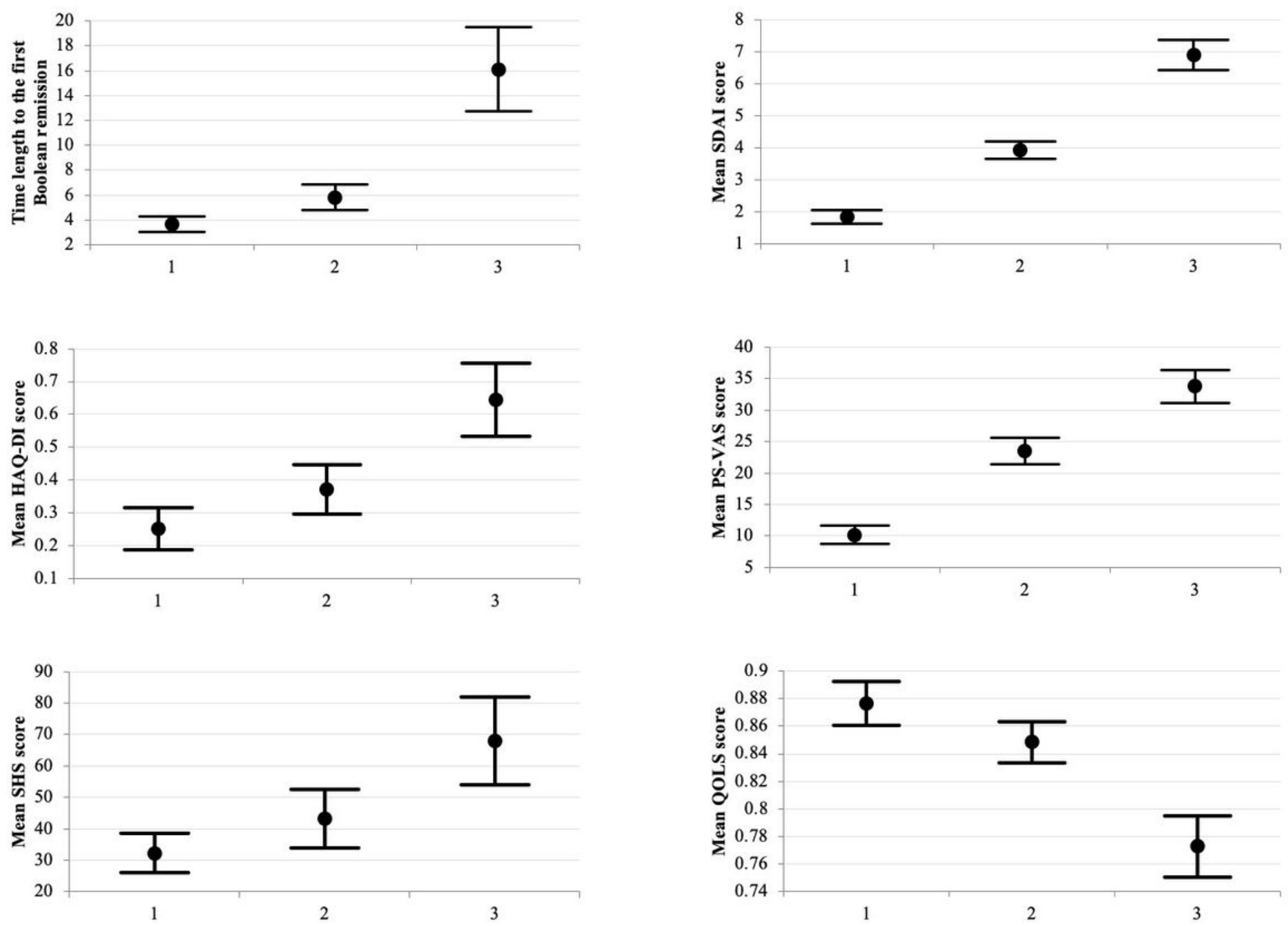

Figure 3

\section{Figure 3}

Comparison among Boolean remission rate groups. 1, a patient group whose Boolean remission rate was $60 \%$ or more ; 2 , a patient group whose Boolean remission rate was less than $60 \%$ and $30 \%$ or more ; 3 , a patient group whose Boolean remission rate was less than 30\%. Error bars represent $95 \%$ confidence interval $(95 \% \mathrm{Cl})$. Every parameter in the group 3 demonstrated significantly worse results than in the other two groups. 


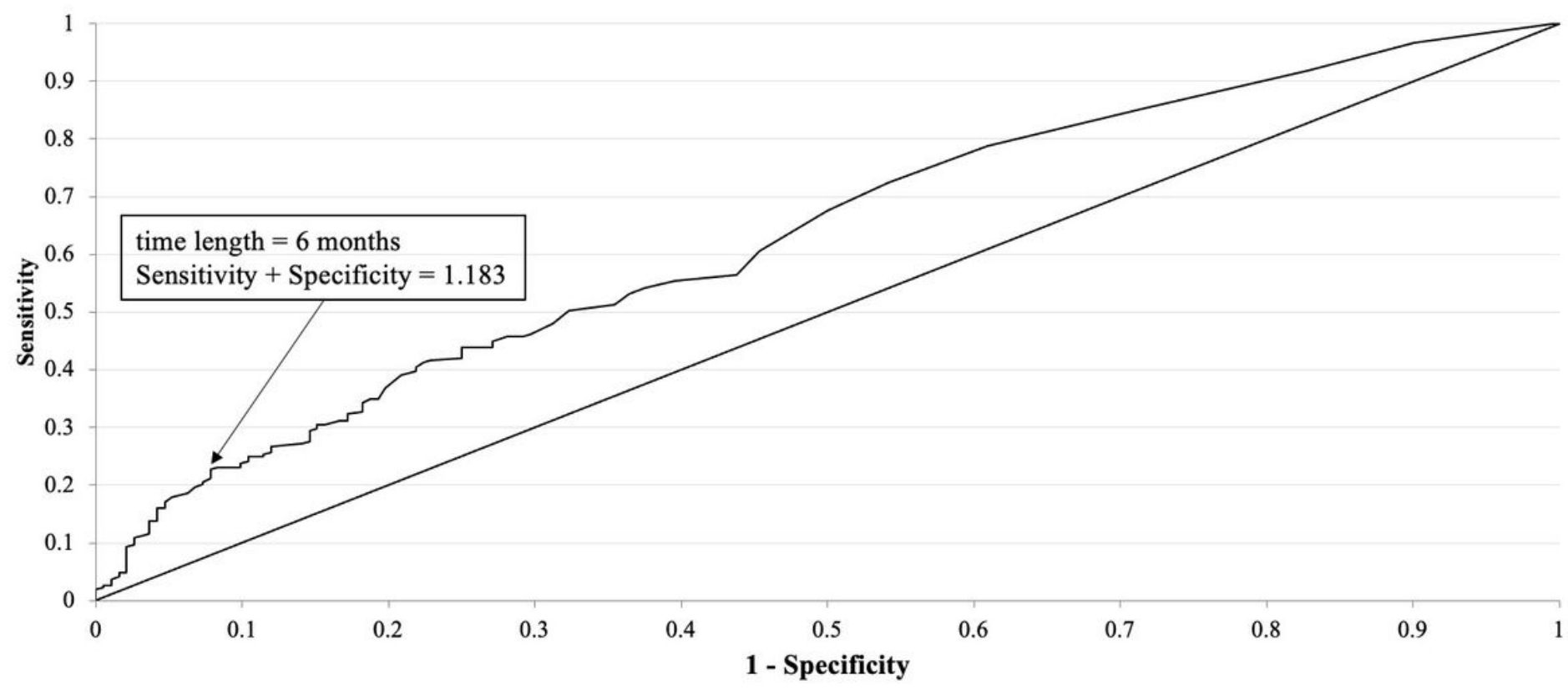

Figure 4

\section{Figure 4}

ROC curve of time length for attaining SDAl remission equivalent (SDAI $\leq 3.3$ ) as a mean value after acquisition first Boolean remission of the patients analyzed in the study. Area under the curve was 0.632. 